\title{
Manipulating larval supply in the field: a controlled study of marine invasibility
}

\author{
Graeme F. Clark* , Emma L. Johnston
}

School of Biological, Earth and Environmental Science, University of New South Wales, Sydney, New South Wales 2052, Australia

\begin{abstract}
In order to gather experimental data to test theories of invasion biology, ecologists have recently adopted a rigorous experimental approach in which community traits and propagule supply are manipulated independently. However, these studies have been limited to terrestrial systems and their generality is not well understood. We conducted a manipulative field experiment to test the relationship between common human disturbances and invasibility in hard-substrate marine epifaunal communities. A larval dosing technique was developed to allow marine experimental units to be dosed with a controlled supply of propagules under field conditions. Six month old assemblages were exposed to 3 fully crossed factors of (1) physical disturbance, (2) chemical disturbance, and (3) timing of larval dose relative to the disturbances. Physical disturbance was shown to increase the invasion success of the introduced species, Bugula neritina, up to $30 \mathrm{~d}$ following the disturbance. This was mainly through an increase of recruitment onto primary space, however physical impacts with an antifoulant surface also led to increased recruitment on secondary space. After $15 \mathrm{~d}$, B. neritina recruits on primary space were found to be larger than recruits on secondary space, suggesting an elevated threat of invasion through primary recruitment. Natural recruitment of barnacles, ascidians, and sedentary polychaetes was also increased by physical disturbance, although these effects were weaker and varied between taxa and sampling times. This study supports the theory that disturbance facilitates invasions in marine epifaunal communities, and contributes a new technique of manipulating propagule supply in the marine environment.
\end{abstract}

KEY WORDS: Invasion biology $\cdot$ Disturbance $\cdot$ Propagule supply $\cdot$ Recruitment $\cdot$ Marine ecology · Ecotoxicology $\cdot$ Fouling communities $\cdot$ Bugula neritina

Resale or republication not permitted without written consent of the publisher

\section{INTRODUCTION}

The rate of biological invasion has increased exponentially over the past few centuries, and now poses a major threat to global biodiversity (Mack et al. 2000). Current understanding of the mechanisms that govern invasions is limited, and seemingly inconsistent patterns have defied attempts to produce a single, unified theory (Davis et al. 2000). These complications are widely attributed to the number of factors that covary with invasions, such as disturbance, species diversity, and propagule supply (Naeem et al. 2000). To partition the relative importance of each of these factors, terrestrial ecologists have recently adopted a rigorous experimental approach, independently manipulating com- munity traits and propagule supply in replicate plots (Burke \& Grime 1996, Tilman 1997, Levine 2000). These studies have produced the first empirical evidence with which to test invasion theory (Tilman 1999), but have so far been confined to terrestrial systems. Many parallels exist between terrestrial plants and hard-substrate marine benthic communities (Connell 1978), since both contain sessile organisms that compete for simple resources such as space and nutrients. There is, however, evidence that suggests considerable differences in the mechanisms governing invasions in the marine and terrestrial domains (Grosholz 1996, Ruiz et al. 2000), and the various theories of invasion ecology need to be tested in marine environments before we can understand their generality. 
Elton (1958) proposed that frequently disturbed ecosystems are more susceptible to invasion than less disturbed ecosystems. The most commonly cited mechanism for this is that disturbance increases resource availability, either by introducing new resources or by decreasing resource-use by resident species, and the opportunity for invasion increases accordingly (Davis et al. 2000). This theory provides a basis for examining the influence of disturbance on invasibility, but its predictive power is limited by the wide range of effects that disturbance can impose on the resource base; effects that can vary with the type, intensity and frequency of the disturbance (Hobbs \& Huenneke 1992). Disturbances may, for example, alter the types of resources available (e.g. properties of the substrate, Hobbs \& Huenneke 1992), or introduce components historically unfamiliar to the system (e.g. toxicants, Johnston \& Keough 2002). Multiple disturbances can also produce complex effects, since combined disturbances may be additive (Collins 1987, Duggin \& Gentle 1998) or even synergistic (Hughes \& Connell 1999). Since many invasive species-traits confer a competitive advantage in only a narrow set of environmental conditions (Sher \& Hyatt 1999), the invasive potential of a species is difficult to predict without an empirical test placing the species in a natural environment (Crawley 1987). For the effective application of disturbance-invasion theory to management and conservation strategies, the process needs to be examined with respect to specific species and well-defined disturbance events. We adopt this rationale in testing the effects of common human-induced chemical and physical disturbances on the susceptibility of marine epifaunal assemblages to invasion by an introduced bryozoan, Bugula neritina.

We propose that hard-substrate epifaunal communities in industrialised bays and estuaries are highly vulnerable to invasion, not only due to the abundance of transport vectors that supply non-indigenous propagules (Carlton \& Geller 1993), but also because of high exposure to anthropogenic disturbance (Hall et al. 1998). Physical disturbance commonly occurs through vessel grounding or docking (Hudson \& Goodwin 2001) which typically creates patches of bare substrate that may be colonised by invasive propagules from the plankton. Vessel groundings may also impose an additional chemical disturbance since the majority of shiphulls are coated in antifouling paint (Negri et al. 2002). Those species capable of colonising antifoulant surfaces (e.g. Floerl et al. 2004) might be particularly invasive during these events, as tolerance of antifouling toxins could have the dual effect of facilitating their initial introduction and providing the species with a competitive advantage in the presence of the toxicants. Chemical disturbances can also occur through transient exposure to water-borne pollutants such as heavy- metals (Beck 1996). Copper is one of the most common heavy metals in estuarine waters (McCahon \& Pascoe 1990), and at high concentrations it becomes toxic to marine invertebrates by interfering with metabolic and reproductive processes (Hall et al. 1998). Pollution events may affect the invasibility of assemblages by causing direct mortality, which releases resources (Johnston \& Keough 2003), or by providing a competitive advantage to introduced species, which are more tolerant of pollution than endemic species.

For a disturbance event to facilitate an invasion, it must coincide with a supply of invasive propagules (Ruiz et al. 2000). Non-indigenous propagules supplied to bays and estuaries include those in the ballast waters from vessels (Carlton \& Geller 1993) and those spawned from biota that foul the hulls of vessels (Carlton 1989). The timing of propagule supply relative to a disturbance is likely to influence invasibility, since the levels of available resources will decrease as the community recovers (Johnstone 1986). Experiments that control for propagule supply in marine environments are needed to determine the importance of various inoculation and community characteristics (Ruiz et al. 2000), but the practical difficulties associated with manipulating the supply of live larvae has so far prevented such research. In response to this, we have developed a larval dosing technique that allows us to emulate the seed-addition experiments of terrestrial studies, and thus examine the initial stages of marine invasions.

In the present study we test for a difference in the invasibility of model hard-substrate marine invertebrate communities subjected experimentally to various pollution and disturbance regimes. We estimate invasibility by measuring the recruitment success of the introduced bryozoan Bugula neritina, whose larvae we supply in controlled doses. We chose to use $B$. neritina because (1) of its demonstrated success as an invader, with a widespread distribution throughout industrialised estuaries around the world (Gordon \& Mawatari 1992), and (2) it is capable of colonising antifoulant surfaces (authors' pers. obs.), suggesting a tolerance to common toxicants that may be linked with its invasive success. Inoculation of $B$. neritina is manipulated so that the density of propagule supply can be quantified, and the timing of the larval dose relative to the disturbances can be varied. This study represents the first rigorous test of the disturbance-invasion hypothesis in a marine system through the use of propagule manipulation.

\section{MATERIALS AND METHODS}

Study site. Experiments were suspended from Kurnell Pier, New South Wales, on the southern margin of Botany Bay (Fig. 1) between February and September 


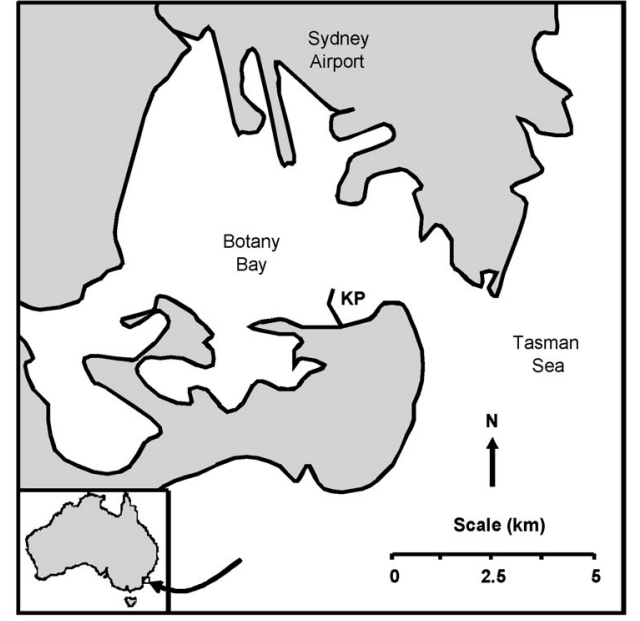

Fig. 1. Map showing study site where experiments were suspended from Kurnell Pier (KP), Botany Bay, NSW, Australia

2003. This is a tidally flushed embayment which accommodates recreational, residential, conservation, and industrial activities (SSROC 2001). Heavy-metal pollution is generally confined to the northern region of the bay (Birch 1996, Hayes et al. 1998), and the study site exhibits low heavy-metal sediment concentrations (Birch et al. 1996).

Experimental design. In February 2003, 60 lightly sanded $11 \times 11 \times 1 \mathrm{~cm}$ black Perspex settlement plates were attached to the underside of five $60 \times 60 \times 1 \mathrm{~cm}$ PVC backing plates. Settlement plates were acid-washed in $10 \%$ (by volume) $\mathrm{HNO}_{3}$ for $24 \mathrm{~h}$ and rinsed in freshwater prior to use. Plates were suspended horizontally from Kurnell Pier at a depth of $2 \mathrm{~m}$ below the low water mark, and assemblages were allowed to develop under natural conditions for 6 mo before manipulations commenced. In August 2003, five 6 mo old settlement plate assemblages were randomly allocated to each of 12 treatments. Treatments consisted of 3 fully crossed, fixed factors of (1) chemical disturbance (2 levels), (2) physical disturbance (3 levels), and (3) timing of larval dose relative to the disturbances (2 levels). The chemical disturbance treatments were conducted $2 \mathrm{wk}$ prior to the physical disturbance treatments, and the larval dosing took place either 1 or $15 \mathrm{~d}$ after the physical disturbance. One replicate of each of the 12 treatments was randomly assigned to a position on each of the 5 backing plates to avoid spatial confounding.

a

b
Chemical disturbance. The chemical disturbance treatments were achieved by dissolving either a copper-spiked or control (non-spiked) plaster block $0.5 \mathrm{~cm}$ beneath the centre of each settlement plate assemblage while submerged on site (Fig. 2a). Assemblages were housed in open 21 plastic containers to enhance the copper dose. Copper-plaster blocks were made following the method of Johnston \& Webb (2000), using AR grade anhydrous copper II sulfate as a reference toxicant. When dissolved, plaster blocks released a pulse of $\mathrm{Cu}^{2+}$ ions, the form of the metal generally considered to be the most toxic to marine invertebrates (Hall et al. 1998). Each copper block was made by dissolving $3.2 \mathrm{~g}$ of $\mathrm{CuSO}_{4}$ in $13 \mathrm{ml}$ of Milli-Q water, and refrigerating the solution at $4^{\circ} \mathrm{C}$ for $60 \mathrm{~min} .15 \mathrm{~g}$ of dental plaster was also refrigerated for $60 \mathrm{~min}$ and then mixed with the copper solution for 15 s. The mixture was poured into an oiled plastic hemispherical mould, $4 \mathrm{~cm}$ in diameter, and a stainless-steel bolt was placed head-down in the centre of the mixture. The bolt had a nut super-glued $3 \mathrm{~cm}$ down the thread so that it might later be securely fastened to the settlement plate without physically disturbing the assemblage. Blocks were oven-dried at $30^{\circ} \mathrm{C}$ for $4 \mathrm{~d}$ to achieve a constant dry weight. Control blocks were made using the same method, except for the addition of $\mathrm{CuSO}_{4}$. Copper dosing

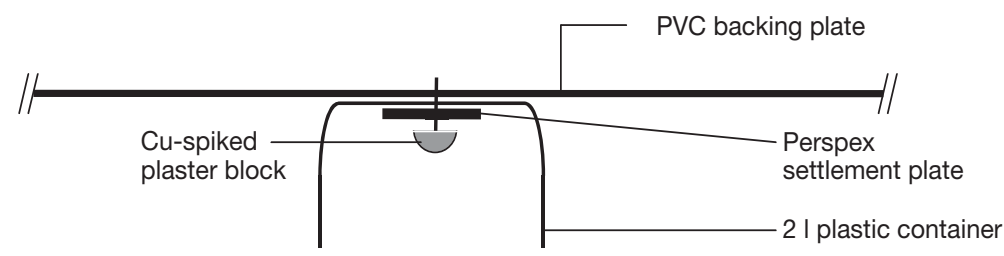
Larval dosing

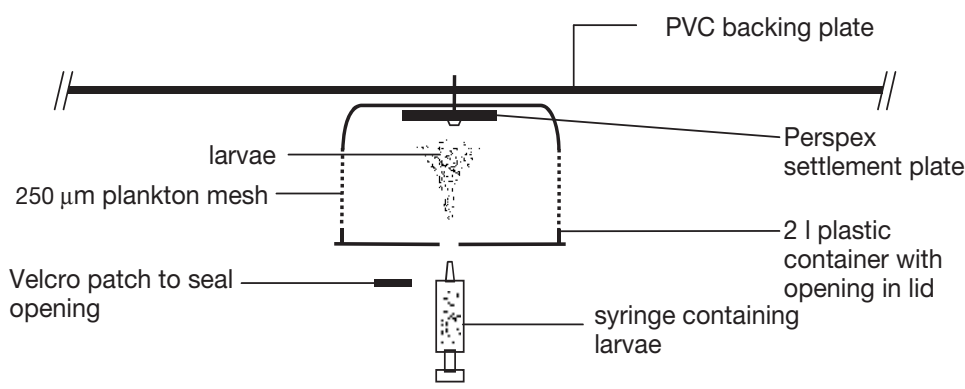

Fig. 2. Schematic representation of apparatus used for (a) copper dosing, and (b) larval dosing. See 'Materials and methods' section for explanation. Settlement plates were transferred between these apparatuses for the chemical disturbance and larval dosing treatments 
Physical disturbance. Settlement plates were equally divided among 3 physical disturbance treatments: (1) no impact, (2) impact with an inert surface, and (3) impact with an antifoulant surface. The impact treatments were intended to represent light shipgroundings, either with a bare ship hull or a ship hull coated in antifouling paint. The impact was simulated by dropping a $17 \mathrm{~kg}$ weight from a height of $30 \mathrm{~cm}$ onto a Perspex plate $(11 \times 11 \mathrm{~cm})$ that was resting on top of the experimental assemblage. The Perspex plate was either left blank or painted with an ablative copperbased antifouling paint $\left(\mathrm{Copper} \mathrm{Coat}^{\odot}\right)$. The plate distributed the force of the impact evenly over the settlement plate, with an average pressure $1400 \mathrm{~Pa}$. Impact treatments were conducted on-site out of water, however exposure to air was minimal $(<15 \mathrm{~s})$ and was also applied to control plates. Settlement plate assemblages were maintained in a pool of local seawater prior to re-immersion at $2 \mathrm{~m}$.

Larval dosing. Assemblages were exposed to a larval dose of the cosmopolitan bryozoan Bugula neritina either 1 or $15 \mathrm{~d}$ following the physical disturbance (hereafter referred to as Larval Dose 1 or 2). This species occurs at Kurnell Pier, but its abundance is seasonal and it was not naturally recruiting during the larval dosing period. Approximately 300 adult colonies of $B$. neritina were collected from the hulls of recreational boats

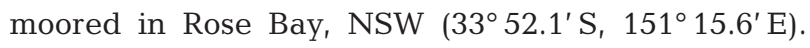
Large reproductive colonies were found growing in dense layers upon the antifouling paint that coated the hulls. Colonies were kept in darkness for $5 \mathrm{~d}$, and were fed with Skeletonema culture every $2 \mathrm{~d}$ to promote the growth of reproductive zooids (ovicells). At the time of dosing, colonies were transported to the field and were exposed to direct sunlight to induce spawning. Light and shade conditions were then alternated in $10 \mathrm{~s}$ intervals to extend larval swimming duration and prevent settlement onto the surface of the container.

Larvae were counted as they were drawn into $60 \mathrm{ml}$ plastic syringes, and rubber stoppers plugged the end of each syringe. Syringes were stored vertically so that an air pocket separated the larvae from the rubber plunger, since larvae tended to settle rapidly on the rubber surface. Syringes were attached to a rope belt and lowered to a SCUBA diver in the water for dosing. Immediately prior to dosing, the syringes were rotated so that the air trapped inside passed over all inner surfaces. This, together with tapping the syringe, encouraged the larvae to remain free-swimming and aided their expulsion. The contents of each syringe were injected into 21 plastic containers via an opening in the lid, and a Velcro patch was affixed over the opening to prevent the escape of larvae. The plastic containers had been bolted to the underside of $60 \times 60 \mathrm{~cm}$ PVC backing plates (Fig. 2b) which were suspended at a depth of $2 \mathrm{~m}$ below the low water mark, and each container housed an experimental assemblage. The sides of each container had been replaced with $250 \mu \mathrm{m}$ plankton mesh to allow water exchange while preventing larval escape. In this way, established assemblages were exposed to a controlled supply of larvae. Lids were removed from the containers after $2 \mathrm{~d}$ so that assemblages were exposed to natural environmental conditions.

Larval Doses 1 and 2 contained 31 (SE $=0.3$ ) and 64 $(\mathrm{SE}=0.8)$ larvae respectively. These were determined by the availability of the larvae at the time of dosing.

An additional 2 treatments were included to estimate the effectiveness of the larval dose. Ten replicate blank settlement plates were submerged in filtered $(0.02 \mu \mathrm{m})$ seawater for $2 \mathrm{~d}$ to allow biofilms to develop. They were then suspended underwater inside larval dosing apparatuses (Fig. 2b) at the time of each larval dosing; 5 received a larval dose and 5 did not. Lids were removed from the containers $2 \mathrm{~d}$ after the larval dose. These plates measured the viability of the larvae in the absence of incumbents, and ensured that settlement of Bugula neritina could be attributed to the larval dose and not to natural recruitment. Plates were also used to quantify the number and size of recruits over the $15 \mathrm{~d}$ following the larval dose. This assisted in the counting of new recruits in the full assemblages by providing an approximate size class of recruits that had settled since the disturbance treatments. All treatments were collected $15 \mathrm{~d}$ after their respective larval dose at times hereafter referred to as Time 1 or Time 2, and were kept in running seawater until census. Hence, treatments exposed to a dose of larvae $1 \mathrm{~d}$ after the physical disturbance (Larval Dose 1) were collected for census at Time 1 (15 d after physical disturbance), and treatments exposed to a dose of larvae $15 \mathrm{~d}$ after the physical disturbance (Larval Dose 2) were collected for census at Time 2 ( $30 \mathrm{~d}$ after physical disturbance).

Census and analysis. New recruits of Bugula neritina, ascidians, barnacles, or polychaetes were counted using a binocular microscope. Ascidian, barnacle, and polychaete recruits were sub-sampled at Time 2 , counting those occurring within four $3 \times 1 \mathrm{~cm}$ areas extending from the centre of the plate (total of $12 \mathrm{~cm}^{2}$ ). All other recruits were counted over the whole plate, excluding a $0.5 \mathrm{~cm}$ perimeter around the edge of the plates and $3 \times 3 \mathrm{~cm}$ area at the centre around the point of attachment. Recruits were recorded as occurring on either primary space or secondary space. Primary space was defined as any inanimate substrate, and included the Perspex plate surface and any calcium carbonate surface that was evidently uninhabited at the time of settlement (e.g. the interior surface of a shattered barnacle shell). Secondary space was defined as the surface of any macro organism. This included the exterior surface of dead but intact organ- 
isms, since the time of death relative to settlement was unknown. For $B$. neritina, the number of terminal branches was recorded for each colony as an index of size. Adults were sub-sampled as above for all treatments, and were defined as any animal that was not considered a new recruit. Organisms were classified to the lowest possible taxonomic level, and the average 2-dimensional percent cover of each animal was recorded. For arborescent species, the percent cover was defined as half of the 2-dimensional area of the colony. The amount of available primary space on each plate was also recorded.

Recruitment success of Bugula neritina was expressed as the proportion of the larval dose that was counted as recruits in the final census (i.e. number of recruits/number of larvae in syringe). Proportions were arcsine (square-root)-transformed. Other taxa were analysed as the density of new recruits on the categories of primary space, secondary space, and total space. Outliers and plots of residuals were examined for each group, and, where appropriate, analysis was conducted on square-root-transformed data. Only those adults with an average of $>5 \%$ cover were included in the analysis. Mean percent cover per plate of each taxa and available space were arcsine (squareroot) transformed.

Three-factor ANOVA tests were conducted for the recruitment success of Bugula neritina onto primary, secondary, and total space, using the factors of physical disturbance (3 levels), chemical disturbance (2 levels), and timing of larval dose (2 levels). Percent cover of the adults and available primary space were also analysed this way. Two-factor ANOVAs were conducted for the densities of naturally occurring recruits, using the factors of physical and chemical disturbance. Two-factor ANOVAs were used for these analyses due to the strong differences in natural recruitment between times, which, if included, would confound changes in recruitment through time that relate to the experimental treatments. If no interactions were found, significant factor effects were explored using a reduced model (one -factor ANOVA with Tukey's test). Where interactions were detected, planned comparisons were used to examine the factor effects and interactions were explored using simple main effects tests (Quinn \& Keough 2002). The size of B. neritina recruits after $15 \mathrm{~d}$ was analysed (ANOVA) to detect a difference between those growing on primary and secondary space, and a difference between those exposed to copper pollution (through either a copper pulse or copper paint) and those that were not. Data for the size of $B$. neritina recruits growing on new, bare settlement plates was only available for Larval Dose 2, so was not analysed but is included in Fig. 5 to allow a visual comparison. Counts of $B$. neritina recruits on larval dosing control plates were examined graphically due to zero recruitment on the non-dosed treatment, and other taxa on these treatments were compared using 2-tailed $t$-tests. All univariate analyses were conducted using SYSTAT v. 10.2.

Due to the strong effects of physical disturbance on invasibility (see 'Results'), we calculated ShannonWiener and Simpson diversity indices using percent cover data for all organisms recorded in assemblages (PRIMER $^{\odot}$ v. 5.2.9). We then used ANOVAs to test for an effect of physical disturbance on species diversity, and regression analysis to test for a relationship between species diversity and overall recruitment success of Bugula neritina.

\section{RESULTS}

\section{Recruitment of dosed species Bugula neritina}

Recruitment success of Bugula neritina onto primary, secondary, and total space was increased by physical disturbance (Table 1, Fig. 3). Tukey's test showed that

Table 1. Bugula neritina. Three-factor ANOVA for recruitment success onto primary, secondary, and total space. Factors are physical disturbance, chemical disturbance, and time of larval dose (either 1 or $15 \mathrm{~d}$ after physical disturbance). Arcsine square-root proportion is used for analysis. Significant results are shown in boldface

\begin{tabular}{|c|c|c|c|c|c|c|c|}
\hline \multirow[t]{2}{*}{ Source } & \multirow[t]{2}{*}{$\mathrm{df}$} & \multicolumn{2}{|c|}{$\begin{array}{l}\text { Recruitment success } \\
\text { onto primary space }\end{array}$} & \multicolumn{2}{|c|}{$\begin{array}{l}\text { Recruitment success } \\
\text { onto secondary space }\end{array}$} & \multicolumn{2}{|c|}{$\begin{array}{l}\text { Recruitment success } \\
\text { onto total space }\end{array}$} \\
\hline & & MS & p & MS & $\mathrm{p}$ & MS & $\mathrm{p}$ \\
\hline Physical & 2 & 0.185 & $<0.001$ & 0.041 & 0.046 & 0.149 & 0.002 \\
\hline Chemical & 1 & 0.013 & 0.344 & $<0.001$ & 0.963 & 0.007 & 0.564 \\
\hline Time & 1 & 0.003 & 0.633 & 0.003 & 0.647 & 0.002 & 0.775 \\
\hline Physical $\times$ Chemical & 2 & 0.013 & 0.402 & 0.012 & 0.397 & 0.020 & 0.392 \\
\hline Chemical $\times$ Time & 1 & 0.001 & 0.754 & 0.048 & 0.054 & 0.043 & 0.152 \\
\hline Physical $\times$ Time & 2 & 0.001 & 0.934 & 0.013 & 0.357 & 0.013 & 0.530 \\
\hline Phys $\times$ Chem $\times$ Time & 2 & 0.002 & 0.875 & 0.002 & 0.831 & 0.002 & 0.929 \\
\hline Error & 48 & 0.014 & & 0.012 & & 0.020 & \\
\hline
\end{tabular}




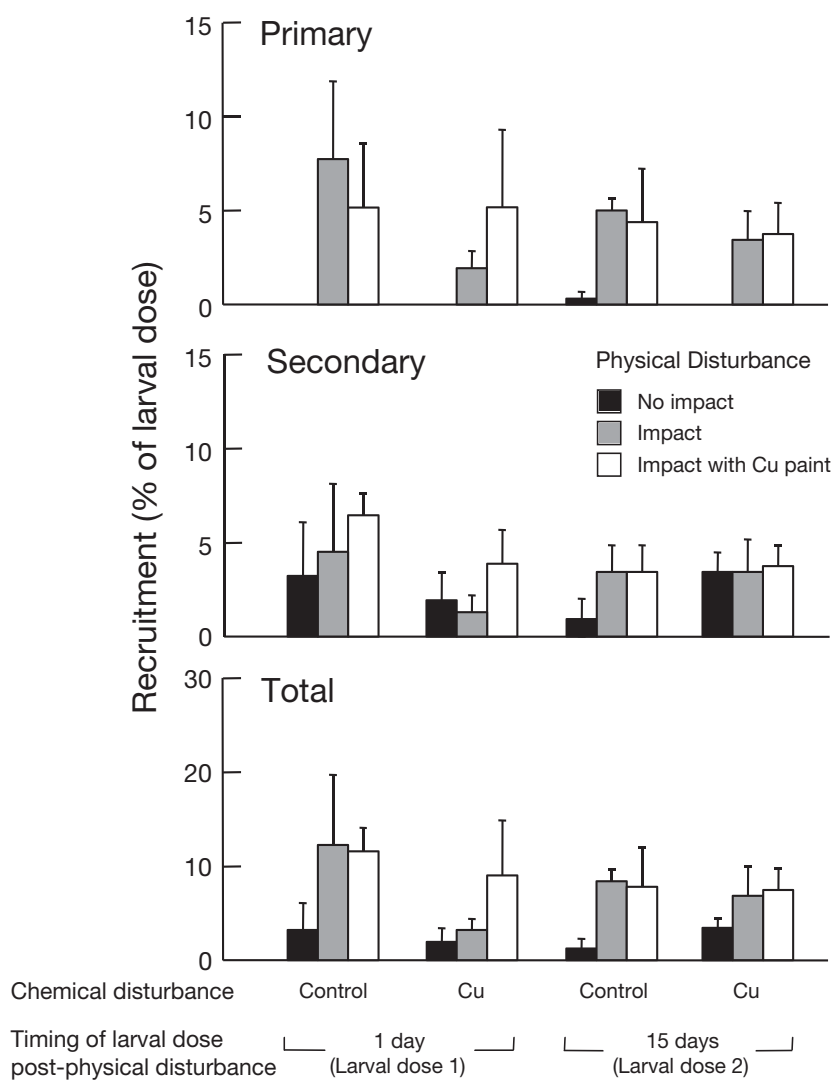

Fig. 3. Bugula neritina. Mean recruitment onto primary, secondary, and total space as a proportion of the larval dose $\pm 1 \mathrm{SE}$ for all treatments. Treatments were collected for census $15 \mathrm{~d}$ after their respective larval doses a. Dosed species

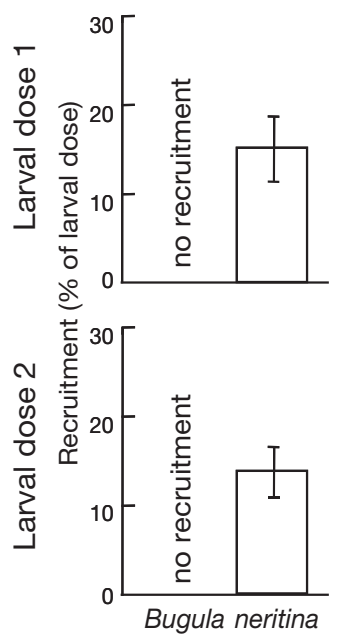

b. Naturally recruiting taxa

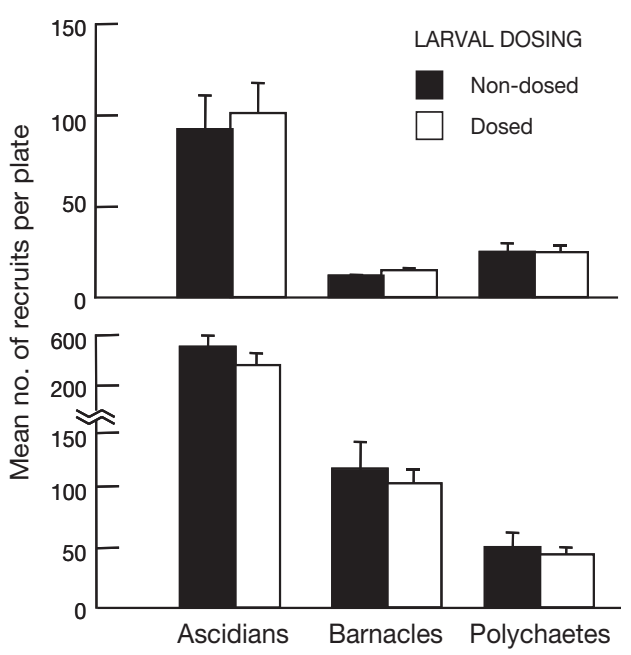

Fig. 4. Larval dosing controls. (a) Mean recruitment success of Bugula neritina, and (b) mean counts of naturally occurring taxa onto bare settlement plates \pm 1 SE. Only recruitment of $B$. neritina differed between dosed and non-dosed treatments
Table 2. Bugula neritina. Two-factor ANOVA for the number of terminal branches on recruits on primary and secondary surfaces after $15 \mathrm{~d}$. 'Time' refers to a difference between larval dosing events. Data are square-root-transformed. Significant results are shown in boldface

\begin{tabular}{|lccc|}
\hline Source & \multicolumn{3}{c|}{ Number of terminal branches } \\
& df & MS & $p$ \\
\hline Surface & 1 & 1.046 & $\mathbf{0 . 0 0 3}$ \\
Time & 1 & 1.398 & 0.065 \\
Surface $\times$ Time & 1 & 0.008 & 0.789 \\
Error & 66 & 0.113 & \\
\hline
\end{tabular}

relative to 'No impact', both 'Impact' and 'Impact with copper paint' increased recruitment success onto primary space $(p<0.001)$ and total space $(p=0.011$, $p=0.001$ respectively). The 'Impact with copper paint' increased recruitment success onto secondary space $(p=0.037)$ (Fig. 3), which is surprising since the amount of secondary space in this treatment was decreased as incumbents were crushed and removed. Neither the copper pulse nor the timing of the larval dose affected recruitment success onto any surface (Table 1, Fig. 3).

In larval dosing controls, Bugula neritina recruits occurred exclusively on dosed plates while the naturally occurring taxa recruited in equal numbers onto dosed and non-dosed plates (Fig. 4). Recruitment success of B. neritina onto dosed plates (percentage of the larval dose that recruited) was consistent between larval dosing events: $15 \%(\mathrm{SE}=3.5)$ and $14 \%(\mathrm{SE}=3)$ for Larval Doses 1 and 2 respectively (Fig. 4a).

At $15 \mathrm{~d}$ old, Bugula neritina colonies on primary space had significantly more terminal branches than those growing on secondary space (Table 2, Fig. 5). Colonies growing on the bare settlement plates at Time 2 had the most terminal branches (Fig. 5), however these were not included in the analysis due an absence of data from Time 1. Copper did not affect the size of colonies, as there was no difference between the chemical disturbance treatments $\left(\mathrm{MS}_{\text {eff }}=0.659, \mathrm{df}=1 ; \mathrm{MS}_{\text {err }}=0.334\right.$, $\mathrm{df}=38 ; \mathrm{p}=0.168$ ) or the 'Impact' and 'Impact with copper paint' treatments $\left(\mathrm{MS}_{\text {eff }}=0.014\right.$, $\left.\mathrm{df}=1 ; \mathrm{MS}_{\text {err }}=0.351, \mathrm{df}=38 ; \mathrm{p}=0.844\right)$.

\section{Natural recruitment of other taxa}

Physical disturbance increased recruitment densities of naturally occurring taxa (ascidians, barnacles, and polychaetes) on primary space at both Time 1 and Time 2 (Table 3, Fig. 6). This effect was significant for both of the physical impact treatments (Tukey's test, $\mathrm{p}<0.05$ ), 


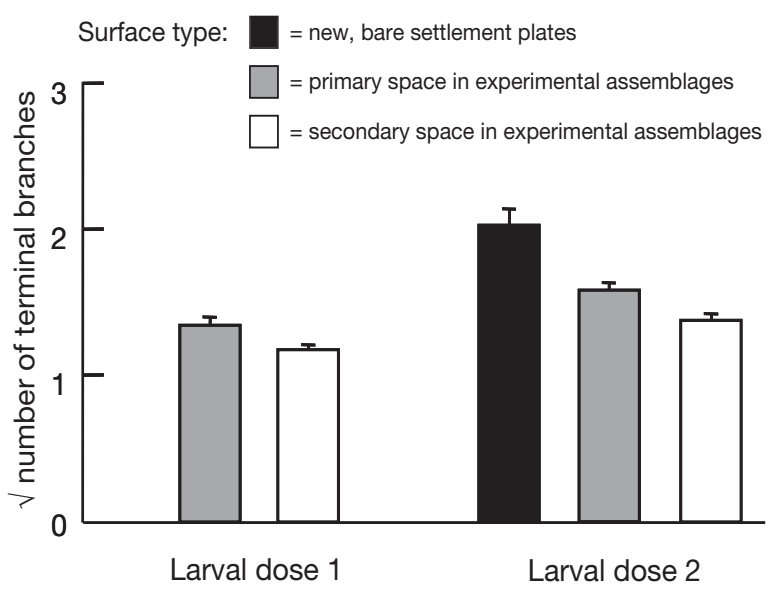

Fig. 5. Bugula neritina. Effect of surface type on the size of recruits after $15 \mathrm{~d}$. Mean number of terminal branches $\pm 1 \mathrm{SE}$ for all treatments. Data for 'new, bare settlement plates' is only available for Larval Dose 2 and was not analysed (see Table 2)

and similar patterns were observed in all of the major taxonomic groups when each was considered separately (ANOVA, $\mathrm{p}<0.05$ ). In contrast to Bugula neritina, the recruitment of these taxa onto secondary space was decreased by the physical disturbance (Table 3, Fig. 6), suggesting a reduction proportional to the availability of this substrate type. The net effect of physical disturbance was to increase total recruitment at Time 2 but not at Time 1 (Table 3, Fig. 6), since at Time 1, the increase in recruitment onto primary space was nullified by the decrease in recruitment onto secondary space. Occasional differences were found in the effects of the 'Impact' and 'Impact with copper paint' treatments (Tukey's tests), but these differences were not consistent and do not appear to be ecologically meaningful.

The larval dosing treatment did not affect the recruitment of any other taxonomic group (2-tailed $t$-tests,

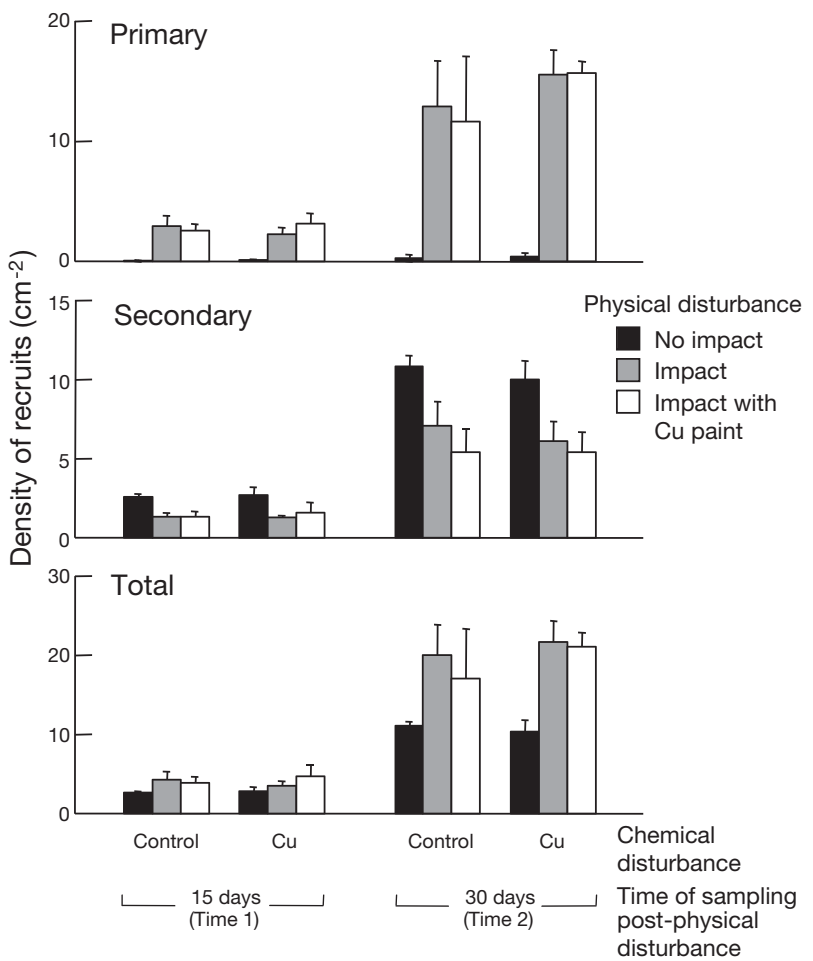

Fig. 6. Mean density of naturally occurring recruits all of taxa onto primary, secondary, and total space \pm 1 SE for all treatments. The majority of recruits were barnacles, ascidians, serpulids or bryozoans

$\mathrm{p} \gg 0.05$ ) (Fig. 4b). Natural recruitment of ascidians, barnacles and polychaetes varied greatly over the $4 \mathrm{wk}$ period, with a dramatic increase in the recruitment of ascidians and barnacles between Time 1 and Time 2 .

\section{Existing assemblages: space cover and liberation}

Bryozoans were the only taxa to occupy a mean cover $>5 \%$ across all treatments. This group was dom-

Table 3. Two-factor ANOVA for natural recruitment onto plates sampled at Time 1 (15 d after physical disturbance) and Time 2 (30 d after physical disturbance). Factors are physical disturbance and chemical disturbance. Data are square-root-transformed densities (recruits $\mathrm{cm}^{-2}$ ). Significant results are shown in boldface

\begin{tabular}{|c|c|c|c|c|c|c|c|c|}
\hline \multirow[t]{3}{*}{ Tir } & \multirow[t]{3}{*}{ Source } & \multirow[t]{3}{*}{ df } & \multicolumn{6}{|c|}{ - Density $\mathrm{cm}^{-2}$} \\
\hline & & & \multicolumn{2}{|c|}{ Primary space } & \multicolumn{2}{|c|}{ Secondary space } & \multicolumn{2}{|c|}{ Total space } \\
\hline & & & MS & $\mathrm{p}$ & MS & $\mathrm{p}$ & MS & $\mathrm{p}$ \\
\hline \multirow[t]{4}{*}{1} & Physical & 2 & 76.834 & $<0.001$ & 8.946 & 0.002 & 4.692 & 0.155 \\
\hline & Chemical & 1 & 0.075 & 0.843 & 0.016 & 0.905 & 0.002 & 0.978 \\
\hline & Phys $\times$ Chem & 2 & 0.926 & 0.614 & 0.019 & 0.982 & 0.635 & 0.763 \\
\hline & Error & 24 & 1.862 & & 1.067 & & 2.326 & \\
\hline \multirow[t]{4}{*}{2} & Physical & 2 & 433.674 & $<0.001$ & 29.313 & 0.001 & 51.464 & 0.005 \\
\hline & Chemical & 1 & 21.507 & 0.142 & 0.874 & 0.605 & 6.242 & 0.383 \\
\hline & Phys $\times$ Chem & 2 & 3.366 & 0.700 & 0.384 & 0.887 & 5.189 & 0.528 \\
\hline & Error & 24 & 9.305 & & 3.187 & & 7.898 & \\
\hline
\end{tabular}


Table 4. Three-factor ANOVA for 2-dimensional available primary space and space occupied by dominant taxa. Factors are physical disturbance, chemical disturbance, and time of sampling (either 15 or $30 \mathrm{~d}$ after physical disturbance). Proportional cover has been arcsine square-root-transformed. Significant results are shown in boldface

\begin{tabular}{|c|c|c|c|c|c|c|c|c|c|c|c|}
\hline \multirow[t]{2}{*}{ Source } & \multirow[t]{2}{*}{$\mathrm{df}$} & \multicolumn{2}{|c|}{$\begin{array}{c}\text { Available } \\
\text { primary space }\end{array}$} & \multicolumn{2}{|c|}{$\begin{array}{c}\text { Fenestrulina } \\
\text { mutabilis }\end{array}$} & \multicolumn{2}{|c|}{$\begin{array}{c}\text { Tricellaria } \\
\text { occidentalis }\end{array}$} & \multicolumn{2}{|c|}{$\begin{array}{c}\text { Beania } \\
\text { magellanica }\end{array}$} & \multicolumn{2}{|c|}{$\begin{array}{c}\text { Other } \\
\text { Bryozoa }\end{array}$} \\
\hline & & MS & $\mathrm{p}$ & MS & $\mathrm{p}$ & MS & $\mathrm{p}$ & MS & $\mathrm{p}$ & MS & $\mathrm{p}$ \\
\hline Physical & 2 & 2.145 & $<0.001$ & 0.224 & $<0.001$ & 0.037 & 0.331 & 0.121 & 0.129 & 0.123 & 0.003 \\
\hline Chemical & 1 & $<0.001$ & 0.949 & 0.013 & 0.465 & 0.016 & 0.495 & 0.053 & 0.338 & 0.040 & 0.154 \\
\hline Time & 1 & 0.012 & 0.482 & 0.032 & 0.245 & 0.057 & 0.193 & 0.071 & 0.269 & 0.045 & 0.129 \\
\hline Physical $\times$ Chemical & 2 & 0.039 & 0.211 & 0.033 & 0.247 & 0.003 & 0.905 & 0.033 & 0.558 & 0.012 & 0.529 \\
\hline Chemical $\times$ Time & 1 & 0.012 & 0.493 & 0.144 & 0.016 & 0.061 & 0.177 & 0.003 & 0.826 & 0.033 & 0.195 \\
\hline Physical $\times$ Time & 2 & 0.060 & 0.097 & 0.001 & 0.953 & 0.003 & 0.918 & 0.033 & 0.560 & 0.007 & 0.700 \\
\hline Phys $\times$ Chem $\times$ Time & 2 & 0.073 & 0.059 & 0.008 & 0.700 & 0.013 & 0.683 & 0.148 & 0.083 & 0.004 & 0.824 \\
\hline Error & 48 & 0.024 & & 0.023 & & 0.033 & & 0.056 & & 0.019 & \\
\hline
\end{tabular}

inated by the native encrusting species Fenestrulina mutabilis and Beania magellanica, and the introduced species Tricellaria occidentalis. The encrusting bryozoans Celleporaria nodulosa, Membranipora perfragilis, Schizoporella errata, and Watersipora subtorquata formed comparatively minor components of the assemblage, and were grouped as 'Other Bryozoa' for the purpose of the analyses. Of these 'Other Bryozoa', $C$. nodulosa is the only native species. Bryozoa were mostly observed growing over a dense base of the Australasian barnacle Balanus variegatus that occupied the primary surface of the plates.

Physical disturbance increased the amount of primary space and reduced the mean cover of Fenestrulina mutabilis and 'Other Bryozoa' (Table 4, Fig. 7). Tukey's test on a reduced model found that both 'Impact' and 'Impact with copper paint' treatments increased primary space $(\mathrm{p}<$ $0.001)$ and reduced cover of $F$. mutabilis ( $\mathrm{p}<0.05)$, but only the 'Impact' treatment reduced cover of the 'Other Bryozoa' ( $p=0.002)$. These effects were consistent over the $30 \mathrm{~d}$ period, with no interaction between physical disturbance and time (Table 4, Fig. 7). A chemical disturbance by time interaction was detected for F. mutabilis (Table 4, Fig. 7), and simple main effects test found that $F$. mutabilis increased from Time 1 to Time 2 on control plates $\left(\mathrm{MS}_{\text {eff }}=0.156, \mathrm{df}=1 ; \mathrm{MS}_{\mathrm{err}}=0.037, \mathrm{df}=28\right.$; $\mathrm{p}=0.049)$ but not on copper-dosed plates $\left(\mathrm{MS}_{\mathrm{eff}}=\right.$ 0.020 , df $=1 ; \mathrm{MS}_{\mathrm{err}}=0.022$, df $=28 ; \mathrm{p}=0.349$ ). Mean percent cover of primary space and each bryozoan is presented for all treatments in Fig. 7.

\section{Species diversity}

Mean species richness per sampled area $\left(12 \mathrm{~cm}^{2}\right)$ of each plate was 10.4 ( $\mathrm{SE}=0.8$ ). Species diversity (Shannon-Wiener and Simpson's diversity
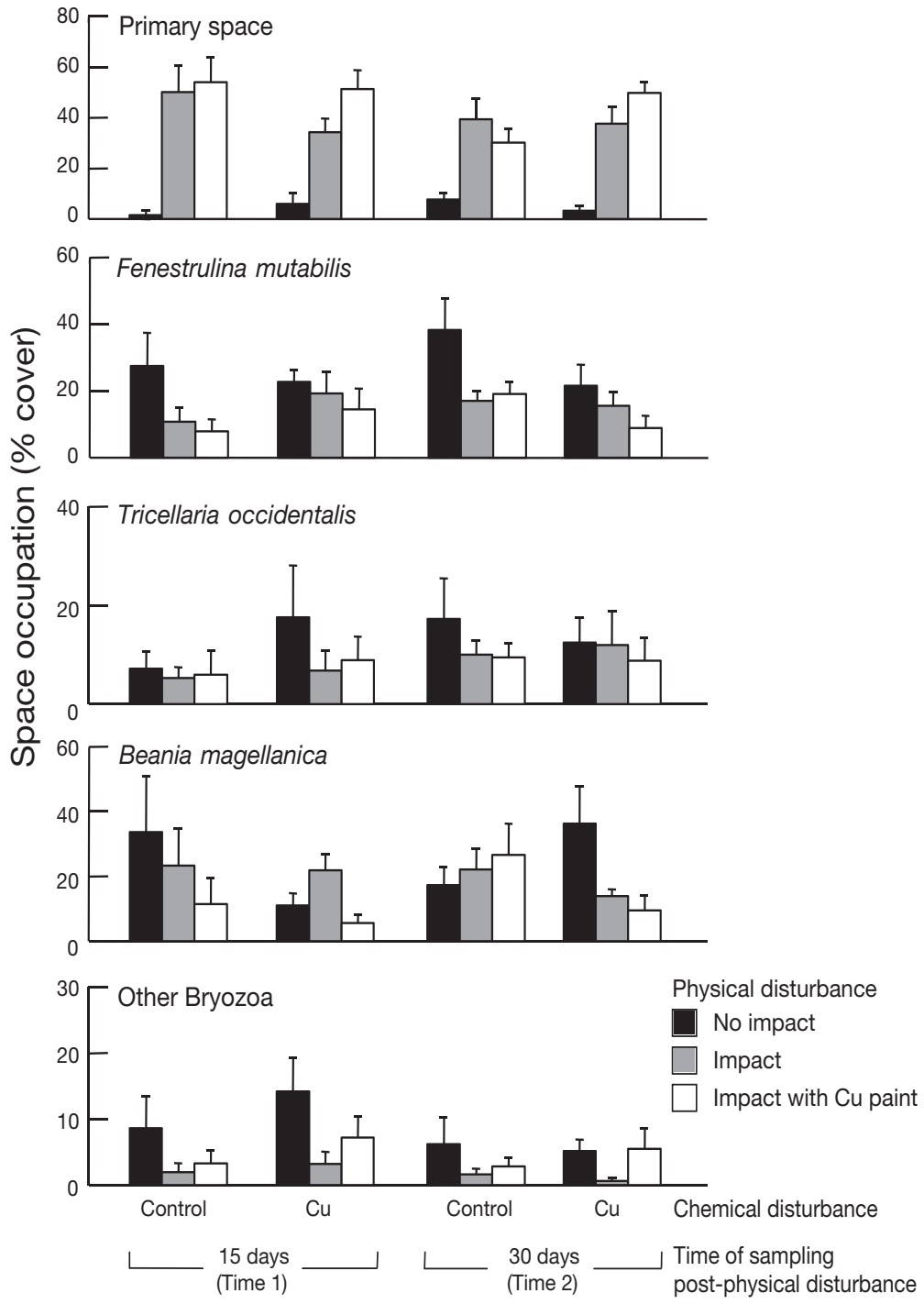

Fig. 7. Mean proportion of 2-dimensional available primary space and space occupied by dominant taxa (Bryozoa) \pm 1 SE for all treatments. 'Other Bryozoa' consist of Celleporaria nodulosa, Membranipora perfragilis, Schizoporella errata, and Watersipora subtorquata 
indices) was not affected by the disturbances $\left(F_{2,57}<\right.$ $0.3, \mathrm{p}>0.3$ ), and showed no relationship to the overall recruitment success of Begula neritina $\left(\mathrm{N}=60, \mathrm{R}^{2}<\right.$ $0.02, \mathrm{p}>0.3)$.

\section{DISCUSSION}

\section{Larval dosing technique}

Our experimental manipulations were successful in exposing established marine invertebrate assemblages to controlled numbers of viable larvae. The recruitment success of Bugula neritina larvae onto bare settlement space was $15 \%$ in both larval dosing controls, while natural recruitment of this species was zero, allowing a rigorous examination of recruitment success relative to disturbance treatment. The development and successful application of the larval dosing technique represents a useful innovation in the study of recruitment phenomena and supply-side ecology. Both the settlement substrate and the characteristics of the larval dose are susceptible to manipulation, producing a device in which community traits and inoculation characteristics may be varied independently under field conditions. This technique could be applied to any sessile aquatic organism with a planktonic larval stage, and for which a sufficient supply of larvae is available. Future experiments could employ the larval dosing technique to explore the importance of various inoculation characteristics to invasion success, such as the frequency, density, and condition of propagule supply, as prescribed by Ruiz et al. (2000).

\section{Disturbance and invasion}

The increased recruitment success of Bugula neritina following a physical disturbance was largely due to the colonisation of primary space liberated by the disturbance. Space is the major limiting resource in epifaunal communities (Dayton 1971, Sutherland 1978), and this study supports the general theory that fluctuation in resource availability is the principal factor governing invasibility (Davis et al. 2000). Burke \& Grime (1996) found similar results in their study of grassland invasibility, showing that invasibility was strongly related to the ability of a disturbance to create bare ground. Although Stachowicz et al. $(1999,2002)$ were primarily interested in the effect of species diversity on the invasibility of marine epifauna, their results also demonstrated that invasibility was most directly related to the ability of an assemblage to sequester primary space. In low-energy environments such as sheltered bays and estuaries, human disturbances may constitute a significant source of resource fluctuations relative to natural agents, and may be partially responsible for the increase in marine invasions over recent years.

While the increase in primary recruitment of both naturally occurring and manipulated species was clearly related to the availability of primary space, the increased secondary recruitment of Bugula neritina (onto incumbents) occurred despite a considerable reduction in secondary space. This effect was only observed on communities impacted with copper paint, and was peculiar to $B$. neritina. The copper-paint residue may have had the direct effect of inducing, or exclusively permitting, settlement of $B$. neritina. Copper-paint residue was visible on the assemblages following the impact, and the increased strength of the positive effect immediately after the disturbance (Time 1) might be attributed to the removal of the residue over time. Early studies of the effects of antifoulants on $B$. neritina found that the paints reduced post-settlement survivorship (Wisely 1963); however these studies were conducted in small containers in which the ambient copper concentration would greatly exceed that in open waters. The parent colonies we used to produce $B$. neritina larvae were collected from dense populations on the hulls of boats coated with antifouling paint, and colonies of another invasive bryozoan, Watersipora subtorquata, have also been found to be resistant to such toxicants (Floerl et al. 2004). If invasive species are found to be consistently more resistant to toxicants than endemic species, chemical pollution may contribute to the distribution of invaders and must be considered in their management.

Physical disturbance not only affected the overall recruit density, but also the proportion of primary versus secondary surface that was colonised. A role of disturbance in facilitating invasions may therefore be related to a difference in fitness (growth and survivorship) between primary and secondary recruits. Size is a commonly used fitness surrogate for modular organisms, with many studies to suggest that demographic traits such as mortality rates, timing of onset of reproduction, and reproductive output, are strongly colony size-dependent (Keough 1989). We found that primary recruits of Bugula neritina were significantly larger than secondary recruits $15 \mathrm{~d}$ post-settlement. This may be due to the effects of bioactive metabolites that inhibit the growth of epibionts (Wahl 1989), or may reflect greater food availability. Recruits onto new, bare settlement plates had the highest growth rates, further suggesting physiological benefits for settlement in isolation or onto inorganic substrata. Disturbances that create primary space may therefore facilitate invasions not only through increasing recruit 
density, but also through the higher fitness of recruits that grow on primary substrates.

The present study also revealed differences in the resilience of species to the physical disturbance, demonstrating a novel mechanism by which species diversity contributes to invasion resistance. Physical disturbance reduced the cover of the hard encrusting bryozoans Fenestrulina mutabilis and the 'Other Bryozoa', yet the arborescent Tricellaria occidentalis and soft-encrusting Beania magellanica species were unaffected by the impact. This is presumably because the brittle, hard-encrusting species were shattered, whereas the arborescent and soft-encrusting species were able to flex and avoid substantial mortality. Diversity in structural morphology moderated the fluctuation of the principal resource, space, and was therefore important in determining invasibility. Much of the invasion literature aims to establish a relationship between species diversity and invasion resistance, usually suggesting that greater diversity leads to increased resource-use and thus precludes invasion (Levine \& D'Antonio 1999). We found no direct relationship between species diversity (H1 and Simpson's $D$ ) and resource availability, but instead found that resource availability was indirectly governed by species composition within a functional group (encrusting Bryozoa). Symstad (2000) also encountered this effect, as she found that the response of particular species to the experimental manipulations (disturbance) was more important than the ability of species to repel functionally similar invaders. This form of stability is related to the concept of functional redundancy, where species that are seemingly redundant may become functionally important in the event of rapid change (Huston 1979, Naeem 1998). The role of species diversity in buffering against disturbance-induced change may therefore represent a key feature in the value of biodiversity to invasion resistance.

Previous studies using the same copper dosing technique found that transient pollution events increased recruitment of a variety of taxa through an indirect effect mediated by competition for space (Johnston \& Keough 2002). We found no effect of a single copper pulse on recruitment, which may be attributed to the absence of a chemical effect on the space occupied by adult organisms within the assemblages. The main space occupiers in our assemblages were adult bryozoans, which are typically less sensitive to pulse pollution events than the solitary ascidians that dominated assemblages in the studies of Johnston \& Keough (2003, 2005), and may account for the null effect at this site. In situ measurements of dissolved copper released from identical plaster blocks at Breakwater Pier, Victoria, Australia, showed that a 2 d pulse of approximately $25 \mathrm{~g} \mathrm{l}^{-1}$ labile copper occurs at the settlement plate surface (Johnston et al. 2003). This exceeds background copper levels and is in the lower range of concentrations used in standard laboratory toxicity tests. Further studies using a suite of toxicants at various concentrations would be useful in determining the pollution events most pertinent to changes in invasibility.

\section{CONCLUSION}

The present study offers an insight into the effects of disturbance on the early stages of an invasion, as disturbance was found to increase the recruitment success of Bugula neritina through a variety of mechanisms. Resource fluctuation was certainly the factor most directly influencing invasibility, yet this was indirectly affected by species diversity, and was supplemented by a positive relationship between $B$. neritina and a copper-based antifoulant. This represents the first marine analogy of the experimental invasion studies in grassland communities (e.g. Tilman 1997, Foster 2002), and provides the basic framework and tools for future research on marine invasions.

Acknowledgements. We thank D. Roberts for his assistance with fieldwork. Thanks to J. Mackie, D. Marshall, and D. Roberts for their comments on draft manuscripts.

\section{LITERATURE CITED}

Beck MB (1996) Transient pollution events: acute risks to the aquatic environment. Water Sci Technol 33:1-15

Birch GF (1996) Sediment-bound metallic contaminants in Sydney's estuaries and adjacent offshore, Australia. Estuar Coast Shelf Sci 42:31-44

Birch GF, Evenden D, Teutsch ME (1996) Dominance of point source in heavy metal distributions in sediments of a major Sydney estuary (Australia). Environ Geol 28:169-174

Burke MJW, Grime JP (1996) An experimental study of plant community invasibility. Ecology 77:776-790

Carlton JT (1989) Man's role in changing the face of the ocean: biological invasions and implications for conservation of near-shore environments. Conserv Biol 3:265-273

Carlton JT, Geller JB (1993) Ecological roulette: the global transport of nonindigenous marine organisms. Science 261:78-82

Collins SL (1987) Interaction of disturbances in tallgrass prairie: a field experiment. Ecology 68:1243-1250

Connell JH (1978) Diversity in tropical rainforests and coral reefs. Science 199(4335):1302-1310

Crawley MJ (1987) What makes a community invasible? In: Gray AJ, Crawley MJ, Edwards PJ (eds) Colonization, succession, and stability. Blackwell Scientific, London, p 429-453

Davis MA, Grime JP, Thompson K (2000) Fluctuating resources in plant communities: a general theory of invasibility. J Ecol 88:528-534

Dayton PK (1971) Competition, disturbance, and community organization: the provision and subsequent utilization of 
space in a rocky intertidal community. Ecol Monogr 41: 352-389

Duggin JA, Gentle CB (1998) Experimental evidence on the importance of disturbance intensity for invasion of Lantana camara L. in dry rainforest-open forest ecotones in north-eastern Australia. Forest Ecology 10:279-292

Elton CS (1958) The ecology of invasions by animals and plants. Methuen, London

Floerl O, Pool TK, Inglis GJ (2004) Positive interactions between nonindigenous species facilitate transport by human vectors. Ecol Appl 14(6):1724-1736

Foster BL, Smith VH, Dickson TL, Hildebrand T (2002) Invasibility and compositional stability in a grassland community: relationships to diversity and extrinsic factors. Oikos 99:300-307

Gordon DP, Mawatari SF (1992) Atlas of marine-fouling Bryozoa of New Zealand ports and harbours. Misc Ser NZ Oceanogr Inst 107:1-52

Grosholz ED (1996) Contrasting rates of spread for introduced species in terrestrial and marine systems. Ecology 77: 1680-1686

Hall LW Jr, Scott MC, Killen WD (1998) Ecological risk assessment of copper and cadmium in surface waters of Chesapeake Bay watershed. Environ Toxicol Chem 17: 1172-1189

Hayes WJ, Anderson IJ, Gaffoor MZ, Hurtado J (1998) Trace metals in oysters and sediments of Botany Bay, Sydney. Sci Total Environ 212:39-47

Hobbs RJ, Huenneke LF (1992) Disturbance, diversity, and invasion implications for conservation. Conserv Biol 6: 324-337

Hudson JH, Goodwin WB (2001) Assessment of vessel grounding injury to coral reef and seagrass habitats in the Florida Keys National Marine Sanctuary, Florida: protocol and methods. Bull Mar Sci 69:509-516

Hughes TP, Connell JH (1999) Multiple stressors on coral reefs: a long-term perspective. Limnol Oceanogr 44: 932-940

Huston M (1979) A general hypothesis of species diversity. Am Nat 113(1):81-101

Johnston EL, Keough MJ (2002) Direct and indirect effects of repeated pollution events on marine hard-substrate assemblages. Ecol Appl 12:1212-1228

Johnston EL, Keough MJ (2003) Competition modifies the response of organisms to toxic disturbance. Mar Ecol Prog Ser 251:15-26

Johnston EL, Keough MJ (2005) Reduction of pollution impacts through the control of toxicant release rate must be site- and season-specific. J Exp Mar Biol Ecol 320:9-33

Johnston EL, Webb JA (2000) Novel techniques for field assessment of copper toxicity on fouling assemblages. Biofouling 15(1-3):165-173

Johnston EL, Webb JA, Keough MJ (2003) Pulse disturbances to the colonization of hard-substrates and in situ determination of copper using diffusive gradients in thin-films (DGT): Quantifying dose and response in the field. Biofouling 19(5):335-345

Johnstone IM (1986) Plant invasion windows: a time-based classification of invasion potential. Biol Rev 61:369-394

Editorial responsibility: Otto Kinne (Editor-in-Chief), Oldendorf/Luhe, Germany
Keough MJ (1989) Variation in growth rate and reproduction of the bryozoan Bugula neritina. Biol Bull 177:277-286

Levine JM (2000) Species diversity and biological invasions: relating local process to community pattern. Science 288: 852-854

Levine JM, D'Antonio CM (1999) Elton revisited: a review of evidence linking diversity and invasibility. Oikos 87:15-26

Mack RN, Simberloff D, Lonsdale WM, Evans H, Clout M, Bazzaz FA (2000) Biotic invasions: causes, epidemiology, global consequences, and control. Ecol Appl 10:689-710

McCahon CP, Pascoe D (1990) Episodic pollution: causes, toxicological effects and ecological significance. Funct Ecol 4:375-383

Naeem S (1998) Species redundancy and ecosystem reliability. Conserv Biol 12(1):39-45

Naeem S, Knops JMH, Tilman D, Howe KM, Kennedy T, Gale S (2000) Plant diversity increases resistance to invasion in the absence of covarying extrinsic factors. Oikos 91: 97-108

Negri AP, Smith LD, Webster NS, Heyward AJ (2002) Understanding ship-grounding impacts on a coral reef: potential effects of anti-foulant paint contamination on coral recruitment. Mar Pollut Bull 44:111-117

Quinn GP, Keough MJ (2002) Experimental design and data analysis for biologists. Cambridge University Press, Cambridge

Ruiz GM, Fofonoff PW, Carlton JT, Wonham MJ, Hines AH (2000) Invasion of coastal marine communities in North America: apparent patterns, processes, and biases. Annu Rev Ecol Syst 31:481-531

Sher AA, Hyatt LA (1999) The disturbed resource-flux invasion matrix: a new framework for patterns of plant invasions. Biol Invasions 1:107-114

SSROC (2001) The tide is turning - final report of the Botany Bay Program. Southern Sydney Regional Organisation of Councils, Sydney

Stachowicz JJ, Whitlach RB, Osman RW (1999) Species diversity and invasion resistance in a marine ecosystem. Science 286:1577-1580

Stachowicz JJ, Fried H, Osman RW, Whitlach RB (2002) Biodiversity, invasion resistance, and marine ecosystem function: reconciling pattern and process. Ecology 83: $2575-2590$

Sutherland JP (1978) Functional roles of Schizoporella and Styela in the fouling community at Beaufort, North Carolina. Ecology 59:257-264

Symstad AJ (2000) A test of the effects of functional group richness and composition on grassland invasibility. Ecology 81:99-109

Tilman D (1997) Community invasibility, recruitment limitation, and grassland biodiversity. Ecology 78:81-92

Tilman D (1999) The ecological consequences of changes in biodiversity: a search for general principles. Ecology 80 : 1455-1474

Wahl M (1989) Marine epibiosis. I. Fouling and antifouling: some basic aspects. Mar Ecol Prog Ser 58:175-189

Wisely B (1963) Effects of antifouling paints on settling larvae of the bryozoan Bugula neritina L. Aust J Mar Freshw Res 18:63-72

Submitted: September 16, 2004; Accepted: March 19, 2005 Proofs received from author(s): July 26, 2005 